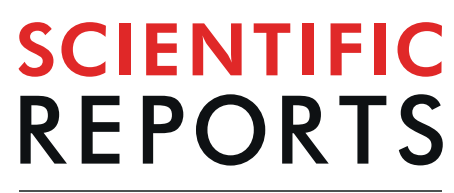

natureresearch

Check for updates

\title{
OPEN Publisher Correction: Syngeneic Mesenchymal Stem Cells Reduce Immune Rejection After Induced Pluripotent Stem Cell-Derived Allogeneic Cardiomyocyte Transplantation
}

\author{
ShoheiYoshida $\mathbb{D}$, Shigeru Miyagawa, Toshihiko Toyofuku, Satsuki Fukushima, \\ Takuji Kawamura, Ai Kawamura, Noriyuki Kashiyama, Yuki Nakamura, Koichi Toda \& \\ Yoshiki Sawa
}

Correction to: Scientific Reports https://doi.org/10.1038/s41598-020-58126-z, published online 12 March 2020

This article contains an error in the Discussion section.

"In this study, the survival of transplanted iPSC-CMs was prolonged; however, the number of engrafted cells was less than $10 \%$ on the 15 th day in the iPSC-CM with MSC group. One limitation of this study was that we did not label MSCs, but the reason as to why engraftment was not permanent might be partially attributed to a decrease in transplanted allogeneic MSCs due to immune rejection after the loss of their immunoprivilege. There are many merits associated with the use of allogeneic MSCs, and not syngeneic MSCs, considering clinical applications; allogeneic MSCs can be prepared well in advance, and are independent of the recipient's condition including disease status and age $\frac{57}{}$. However, allogeneic MSCs were found to be immunoprivileged early after implantation but gradually lost this phenotype $\underline{57,58}$. Recently, methods to prolong the engraftment of allogeneic MSCs have also been reported and the further development of such methods might allow the long-term cell engraftment of allogeneic MSCs 59,60 ."

should read:

"There are many merits associated with the use of allogeneic MSCs, and not syngeneic MSCs, considering clinical applications; allogeneic MSCs can be prepared well in advance, and are independent of the recipient's condition including disease status and age $\frac{57}{}$. However, allogeneic MSCs were found to be immunoprivileged early after implantation but gradually lost this phenotype $\underline{57,58}$. Recently, methods to prolong the engraftment of allogeneic MSCs have also been reported and the further development of such methods might allow the long-term cell engraftment of allogeneic MSCs 59,60 ."

(i) Open Access This article is licensed under a Creative Commons Attribution 4.0 International License, which permits use, sharing, adaptation, distribution and reproduction in any medium or format, as long as you give appropriate credit to the original author(s) and the source, provide a link to the Creative Commons license, and indicate if changes were made. The images or other third party material in this article are included in the article's Creative Commons license, unless indicated otherwise in a credit line to the material. If material is not included in the article's Creative Commons license and your intended use is not permitted by statutory regulation or exceeds the permitted use, you will need to obtain permission directly from the copyright holder. To view a copy of this license, visit http://creativecommons.org/licenses/by/4.0/.

(c) The Author(s) 2020 